\title{
Environmental impact estimation of ceramic tile industry using modeling with neural networks
}

Original Scientific Papers

\author{
Verica Hocenski \\ Keramika Modus d.o.o. \\ Vladimira Nazora 67, Orahovica, Croatia \\ verica.hocenski@gmail.com
}

\author{
Ana Lončarić Božić \\ University of Zagreb \\ Faculty of Chemical Engineering and Technology \\ Marulićev trg 19, Zagreb, Croatia \\ abozic@fkit.hr \\ Nedjeljko Perić \\ University of Zagreb \\ Faculty of Electrical Engineering and Computing \\ Unska 3, Zagreb, Croatia \\ nedjeljko.peric@fer.hr
}

\author{
Denis Klapan \\ J. J. Strossmayer University of Osijek, \\ Faculty of Dental Medicine and Health \\ Crkvena 21, Osijek, Croatia \\ klapandenis@gmail.com \\ Željko Hocenski \\ J. J. Strossmayer University of Osijek, \\ Faculty of Electrical Engineering, Computer Science \\ and Information Technology Osijek \\ Cara Hadrijana 10, Osijek, Croatia \\ zeljko.hocenski@ferit.hr
}

\begin{abstract}
The ceramic tiles industry has a significant environmental impact due to consumption of raw materials, energy and environmental emissions. There are numerous activities on global level in accordance to the principles of sustainable development. This paper presents the development and application of mathematical models of manufacturing processes based on static neural networks for prediction and control of environmental impact of ceramic tiles production process. The neural network learning is made based on known input and output values from the production process. The control of the environmental impact is made on the basis of the output values from the process amounts of correct and faulty ceramic tiles. The model for prediction of correct amount of tiles and percentage of waste with an average error of $1.7 \%$ is presented in this paper. It could be successfully used to estimate and control the environmental influence. A simple model of production process has been applied in the manufacturing process of ceramic tile factory KIO Keramika d.o.o. Orahovica. It produced ceramic tiles using monofiring process according to EN 14411 B III group Part L. The company has introduced and certified management systems according to ISO-9001. and ISO 14001.
\end{abstract}

Keywords: ceramic tiles, estimation, environmental impact, neural networks

\section{INTRODUCTION}

The application of artificial neural networks is based on knowledge of the structure and functioning of the human brain and its great capabilities to solve the complex problems. A great number of neural networks of different structure is used that can basically be divided into static and dynamic [1]. This paper describes the application of static neural network to produce a mathematical model of the production process. This paper uses two-layer neural network shown in Fig.1.

The neural networks have a large application area. They are used to solve problems in various fields of science, technology, medicine, meteorology, economics, sociology, biology, ecology, etc. The paper [2] describes the results of the evaluation of nonlinear systems by neural networks and comparison of two techniques to select the optimal number of model parameters. Paper [3] presents the study of the structure and role of the learning algorithm in real time applications of neural networks is presented. Another paper published later [4] describes the successful application of neural networks to control the gas of the vehicle. In reference [5] the authors propose a new type of neural network to evaluate the robustness of tires with road friction. The application of neural networks for wind gusts is described paper [6] for predicting the spatial distribution of the wind. The paper published in 2010 describes a successful application of neural networks for automatic sorting of ceramic tiles [7]. 


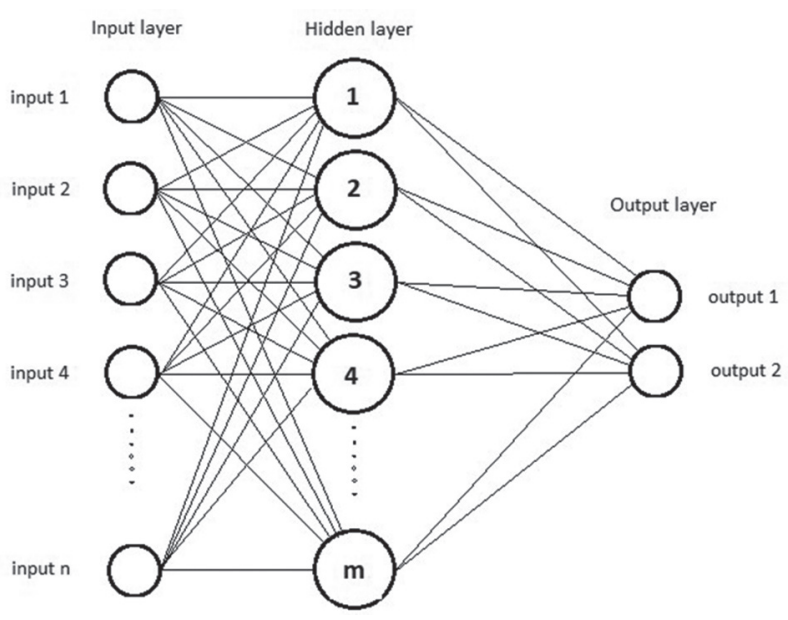

Fig. 1. Schematic view of two-layered neural network

Neural networks in meteorology has been presented in the 2009 for predicting wind flow [8]. The paper published in 2010 describes the application of neural networks to overlook flood [9]. The neural networks could be used to recognize faces and identify persons. The modelling of influence of waste rubber by neural networks is described in 2019 [10]. Another flood-routing modelling with neural networks is described in [11] and electricity consumption forecasting by neural networks is described in 2019 [12].

A simple model of the production process has been applied to the manufacturing process of ceramic tiles factory KIO Keramika d.o.o. in Orahovica that produces ceramic tiles using mono-firing technology according to EN 14411 Group B III Part L [13]. The company had been certified for management systems according to ISO-9001 [14]. and ISO 14001 [15]. The factory produces ceramic tiles for wall and floor interior lining of various sizes and design by declared norm EN - 14411 [13]. The diagram of the production process is shown in Fig. 2 [16].

The tiles are manufactured by mono-firing technology for wall and floor tiles. The production process consists of a series of sub-processes: the preparation of raw materials, the preparation of granules for pressing, shaping, drying of raw tiles, glazing, firing, sorting and packaging [17].

Preparation of raw materials. The mixture of raw materials for ceramic tiles production are made from several components: clay, granite and dolomite. The clay is exploited from the mine in factory area. The clay is excavated and arranged in lots. After aging the clay is taken to a warehouse. The materials (frit and pigments for glaze) are delivered by trucks from suppliers mostly from Italy, Spain and other countries.

Preparation of granules for pressing. The mixture of components is grinded by wet process (along with water and electrolyte) with the addition of ceramic wastes in a ball mill. After milling the material is atomized into granules and kept in silos from which it is fed to the press.
The shaping of tiles is made by dry pressing. The hydraulic presses of high power and productivity are used. The granulate needs to be pressed under specific pressure. The tools enable pressing of several plates simultaneously.

Drying of raw tiles. The pressed tiles are introduced into the dryer. The tiles are dried gradually by warming. The drying time depends on the type of tiles (for wall or floor covering), and the necessary moisture content of raw tiles.

Glazing process. After drying tiles come to glazing. A layer of glaze is applied to the tiles and decorating is done. The tiles are stacked in wagons and taken to the oven for firing or baking.

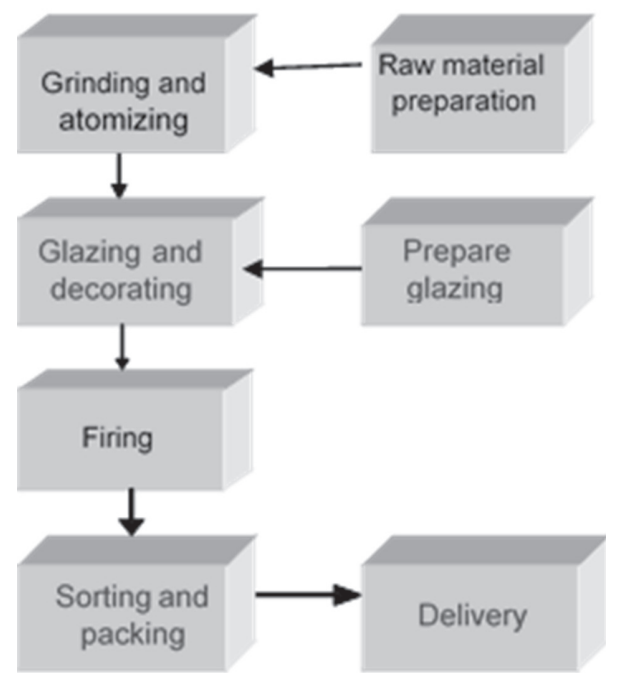

Fig. 2. Schematic view of production process

Firing or baking of tiles takes place in an oven by a mono-firing process at a temperature between 1050 and $1200^{\circ} \mathrm{C}$. After cooling, the tiles are taken for sorting.

Sorting and packing. After baking, the tiles are inspected for surface defects. According to the results of the inspection, they are classified into classes and the waste is separated according to the EN-14411 standard, packed in cardboard boxes and placed on pallets.

\section{MODEL OF PRODUCTION PROCESS}

The static neural network is a development environment for making mathematical model of the production process that includes a software package with MATLAB tools for neural networks (nntool and nftool) suitable for studies of the structure of neural network and evaluating the results. It is applied the two-layer feedforward (feed-forward) network with sigmoid activation function in the hidden layer and linear activation function in the output layer. Learning was performed by Levenberg-Marquardt algorithm with a retroactive effect. The mathematical model of the production process by static neural network is used to simulate the manufacturing process. The evaluation of the actual results is obtained by measurements [16] [18]. 


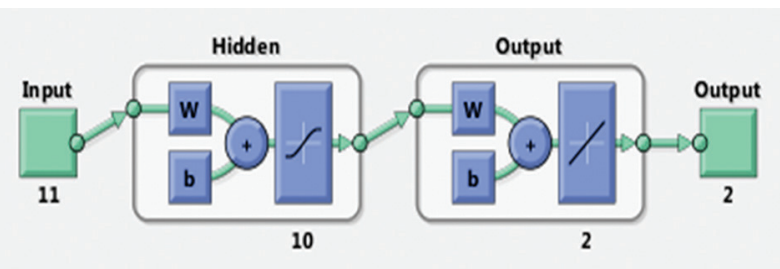

Fig. 3. Simple neural network model with 11 inputs and 2 outputs, which has 10 neurons in the hidden layer and 2 neurons in the output layer.

Research of best neural network structure is a learning process in which the network changes its parameters and coefficients trying to achieve desired target output values based on the known inputs, selected input data sets and the corresponding set of known output data. The input data are obtained by analyzing the mono-firing production process technology in the preliminary assessment phase.

Table 1. Inputs and outputs of process model

\begin{tabular}{|c|c|c|}
\hline Inputs & $\begin{array}{l}\text { A simple model } \\
\text { Process phase }\end{array}$ & Outputs \\
\hline $\begin{array}{c}\text { clay } \\
\text { dolomite } \\
\text { electrolyte } \\
\text { water } \\
\text { gas atomizer }\end{array}$ & $\begin{array}{l}\text { preparation of slip } \\
\text { and granules }\end{array}$ & \multirow{4}{*}{$\begin{array}{l}\text { - correct tiles } \\
\text { - waste tiles }\end{array}$} \\
\hline gas dryer & $\begin{array}{l}\text { pressing tiles and } \\
\text { drying }\end{array}$ & \\
\hline $\begin{array}{c}\text { frit } \\
\text { engobe } \\
\text { pigment } \\
\text { other materials }\end{array}$ & $\begin{array}{l}\text { glazing and } \\
\text { decoration }\end{array}$ & \\
\hline gas firing & firing & \\
\hline
\end{tabular}

The inputs are monthly consumption of raw materials used in the preparation of materials, such as clay, dolomite, electrolyte, water, gas in atomizer, gas for drying raw tiles and burning, raw material for the glazing of frit, pigments and other raw materials. A simple model is made according to a set of 11 input variables on the consumption of raw materials and manufacturing process in the year 1998. Two output values were chosen: the correct amount of tiles that meet the requirements of the technical standard EN 14 411: 2004 [13] and the percentage of waste tiles, that are not usable for the primary purpose, because they are not in compliance with the requirements of technical standards [14]. The values of input and output are presented by a simple process stages in Table 1.

\section{LEARNING A SIMPLE PRODUCTION MODEL}

The learning process of simple model neural network was performed with 10, 15 and 20 neurons in the hidden layer. The evaluation of properties of the obtained neural network structure was completed using the mean squared error (MSE) and regression analysis. Only some of the results of learning network with 20 neurons in the hidden layer are shown in Table 2 . The table shows the order of training ( $\mathrm{Tr}$ ), the mean error MSE, regression $\mathrm{R}$, performance $\mathrm{P}$, gradient $\mathrm{Gr}$, Mu (parameter $\mu$ ) and the number of iterations $\mathrm{Ni}$ of that training. The lowest MSE gives the best performance $P$. The regression shows how close are the model output and target value.

Table 2. Results of learning of network with 20 neurons in hidden layer

\begin{tabular}{|c|c|c|c|c|c|c|}
\hline \multirow{2}{*}{$\operatorname{Tr}$} & \multicolumn{6}{|c|}{ Learning results } \\
\hline & MSE & $R$ & $P$ & Gr & Mu & $\mathrm{Ni}$ \\
\hline 1. & $3,293 e^{-3}$ & 0,941 & $1,9 e^{-14}$ & $9,24 e^{-8}$ & $1,0 \mathrm{e}^{-7}$ & 4 \\
\hline 2. & $5,257 e^{-3}$ & 0,919 & $1,4 e^{-19}$ & $1,5 e^{-10}$ & $1,0 \mathrm{e}^{-7}$ & 4 \\
\hline 3. & $2,385 e^{-13}$ & 0,999 & $2,3 e^{-13}$ & $5,5 e^{-7}$ & $1,0 \mathrm{e}^{-6}$ & 3 \\
\hline 4. & $1,839 \mathrm{e}^{-5}$ & 0,997 & $3,9 e^{-18}$ & $1,1 e^{-9}$ & $1,0 \mathrm{e}^{-7}$ & 4 \\
\hline 5. & $1,108 \mathrm{e}^{-2}$ & 0,889 & $4,0 e^{-13}$ & $7,2 e^{-7}$ & $1,0 e-7$ & 4 \\
\hline 6. & $3,055 \mathrm{e}^{-4}$ & 0,996 & $4,3 e^{-14}$ & $5,8 e^{-8}$ & $1,0 \mathrm{e}^{-6}$ & 3 \\
\hline 7. & $6,009 e^{-3}$ & 0,909 & $2,5 e^{-11}$ & $2,4 e^{-6}$ & $1,0 \mathrm{e}^{-6}$ & 3 \\
\hline 8. & $8,325 e^{-3}$ & 0,914 & $3,8 e^{-13}$ & $6,9 e^{-7}$ & $1.0 \mathrm{e}^{-7}$ & 4 \\
\hline 9. & $1,243 \mathrm{e}^{-19}$ & 1,000 & $1,2 e^{-19}$ & $1,9 e^{-10}$ & $1,0 \mathrm{e}^{-7}$ & 4 \\
\hline 10. & $8,168 \mathrm{e}^{-4}$ & 0,981 & $1,3 e^{-12}$ & $8,3 e^{-7}$ & $1,0 \mathrm{e}^{-6}$ & 3 \\
\hline 11. & $1,687 e^{-6}$ & 0,999 & $8,3 e^{-12}$ & $2,4 e^{-6}$ & $1,0 \mathrm{e}^{-6}$ & 3 \\
\hline 12. & $1,708 \mathrm{e}^{-17}$ & 0,999 & $1,7 e^{-17}$ & $3,8 e^{-9}$ & $1,0 \mathrm{e}^{-7}$ & 4 \\
\hline 13. & $5,155 \mathrm{e}^{-3}$ & 0,935 & $4,1 e^{-16}$ & $5,9 e^{-9}$ & $1,0 \mathrm{e}^{-7}$ & 4 \\
\hline 15. & $6,029 e^{-11}$ & 0,999 & $6,0 e^{-11}$ & $6,4 e^{-6}$ & $1,0 e^{-6}$ & 3 \\
\hline
\end{tabular}

The network with 20 neurons in the hidden layer and the smallest difference between the real output values and desired target was selected for model verification of the production process. The values for the selected network used for further testing are shown in Table 3. 
Table 3. The ninth best resulting learning network with 20 neurons in hidden layer.

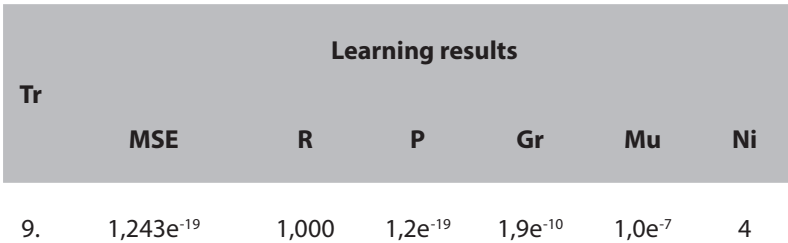

The results of ninth learning network with 20 neurons in the hidden layer are presented in the following pictures. The ninth learning network has the best result as the MSE and performance are the lowest and regression is one from all training networks. The output from views that have been obtained for the selected network to test the model are presented in pictures below. Fig. 4 shows a histogram of error as the difference between target and output.

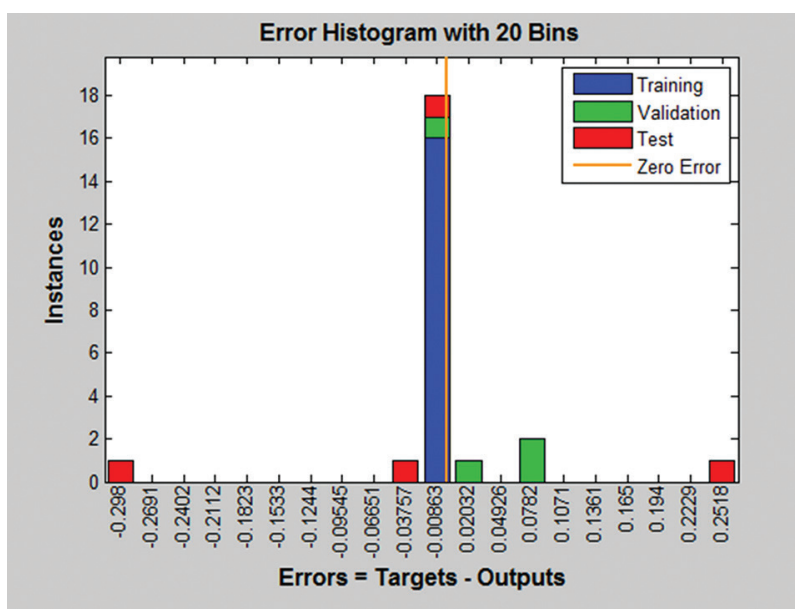

Fig. 4. Histogram and progress of ninth learning with 20 neurons in the hidden layer.
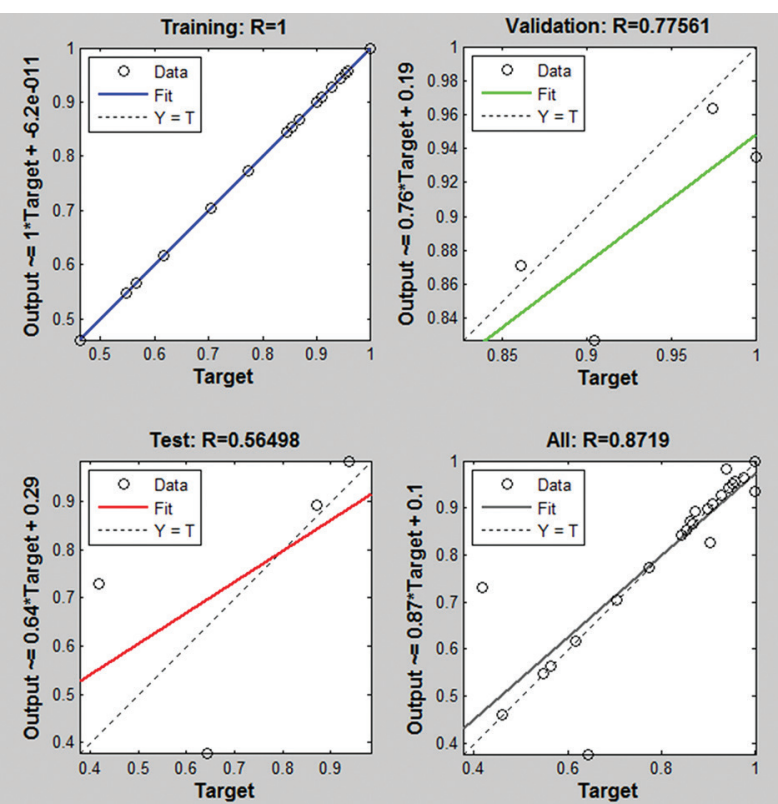

Fig. 5. Regression and progress of ninth learning with 20 neurons in the hidden layer.

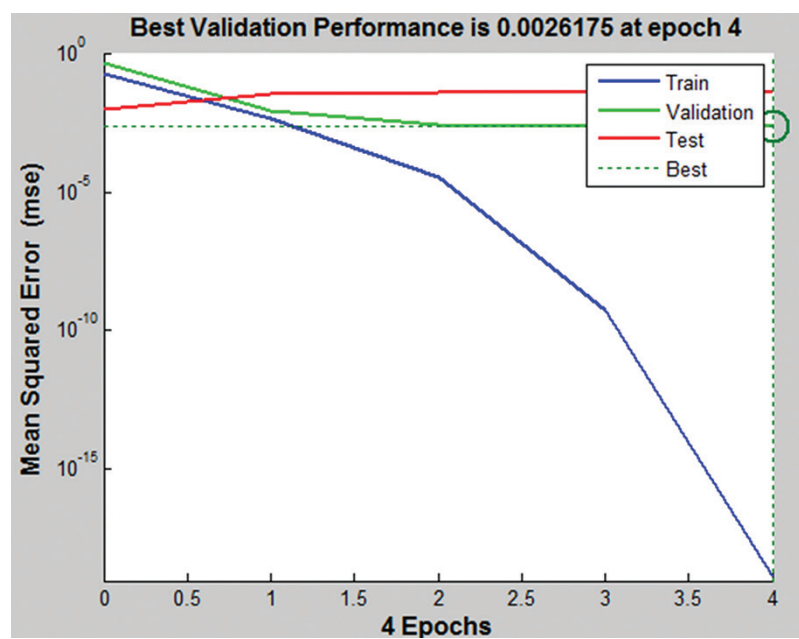

Fig. 6. MSE diagram of ninth learning with 20 neurons in the hidden layer.

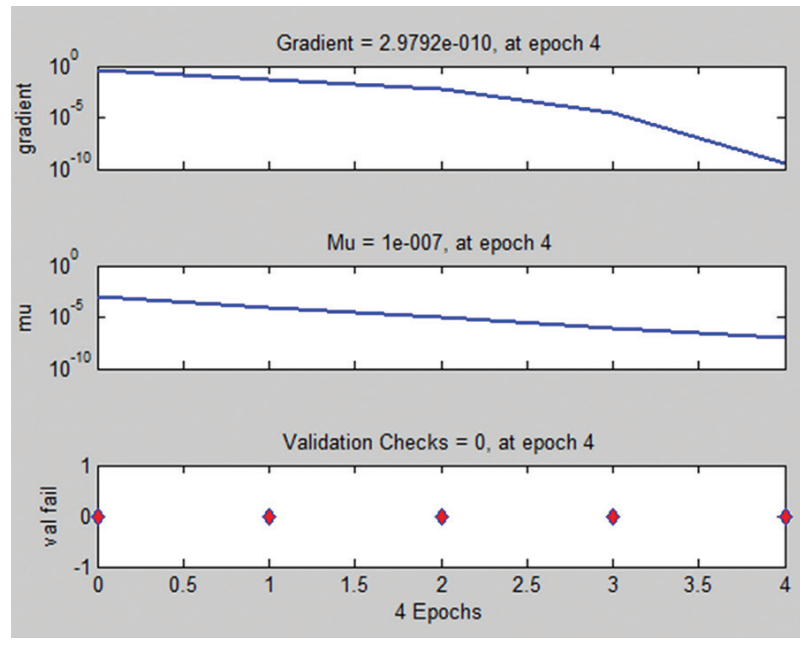

Fig. 7. Gradient diagrams, Mu (parametar $\mu$ ) and validation of ninth learning with 20 neurons in the hidden layer.

Due to the high MSE of results modeling is continued on network structure and parameters obtained by ninth learning with 20 neurons in the hidden layer.

The Fig. 5 to Fig. 7 are presenting the results of modeling tool and they are used for comparison between trainings to enable the choice of the best network. The number of epochs or iterations depends on getting the best result in some training as presented in Table 2 .

\section{RESULTS OF SIMPLE MODEL}

The network with parameters shown in Table 3 obtained by ninth learning with 20 neurons in the hidden layer was selected to test the models of the production process. The application of a simple model to the data by months of production of ceramic tiles is used for years 1999, 2000, 2001, 2002, 2003, and 2004, 2005 and 2006. The obtained results are for correct amount of tiles and waste tile amount for each year. The model error was calculated by comparing the actual values of output variables obtained by measuring. 


\subsection{MODEL RESULTS FOR CORRECT TILES}

Fig. 8 shows the results of total annual quantity of produced correct tiles and the total quantity the correct tiles in $\mathrm{m}^{2}$ per year obtained by model using the neural network from ninth learning with 20 neurons in the hidden layer. A comparison between the values of the production process for the correct amount tiles for the observed period of 1999 - 2006 year and the values obtained by the model and the model error was calculated for each year. Fig. 9 shows the annual output error for the correct tiles compared with the average error that is around $6.5 \%$.

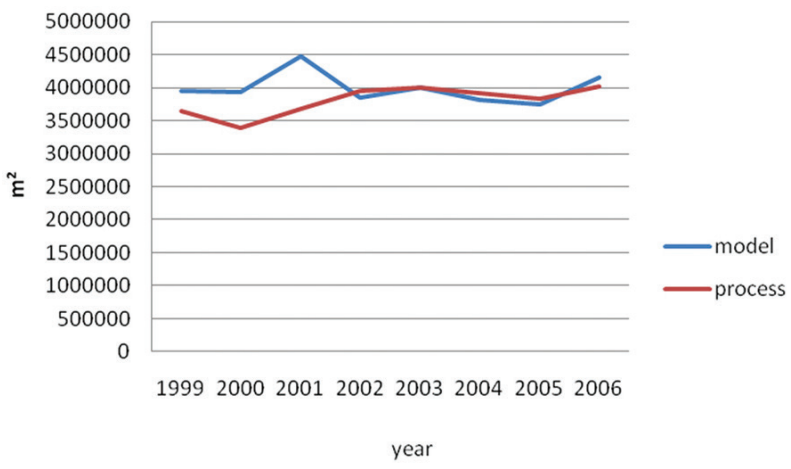

Fig. 8. Comparative review of output from the process and the amount obtained by model and by year.

From Fig. 9 it can be seen that after year 2002 model error decreases and is on average $4.8 \%$

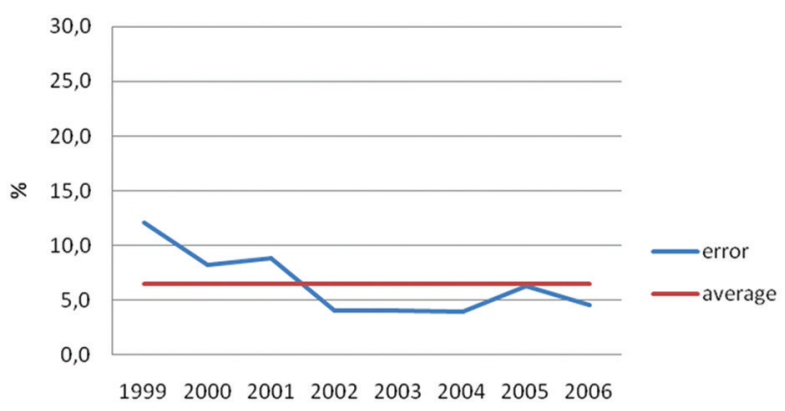

Year

Fig. 9. Model error for the correct amount tiles per year and the average error.

The deviation of the results obtained by the model and real production within one year by month was analyzed. Fig. 10 shows the output of the correct tiles per month in 2006 for quantity and value of the correct tiles obtained using a simple model with a neural network for ninth learning with 20 neurons in the hidden layer.

The Fig. 10 shows the largest variations are observed in January and December 2006.

The largest deviations are in winter months of December and January. Fig. 11 shows the model error percentages for the correct amount of tiles in months of year.
From Fig. 12 it can be seen that the model error is the largest in the winter months and especially at the beginning and end of the year. The average model error for December and January between 1999 and 2006 is around $13.1 \%$. That is twice as much as the average error $(6.5 \%)$ in the observed period. The larger model error in December and January can be explained by the fact that due to the holidays there are fewer working days in December. The first week of January is the overhaul of equipment, and production stops. It is caused by the lower production in the winter months and the problems of delivery of natural gas. Because of the low temperatures, gas consumption is higher, so it was a big turn off consumers.

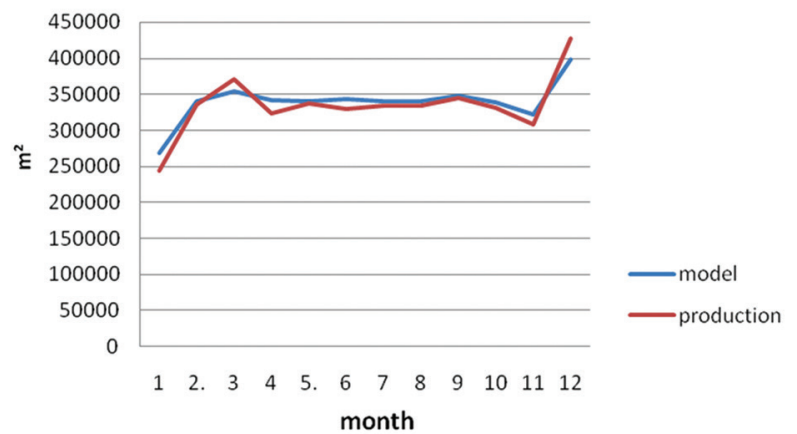

Fig. 10. Amount of the correct tiles and tiles obtained by a simple model of neural network in $\mathrm{m} 2$ in year 2006 the by month.

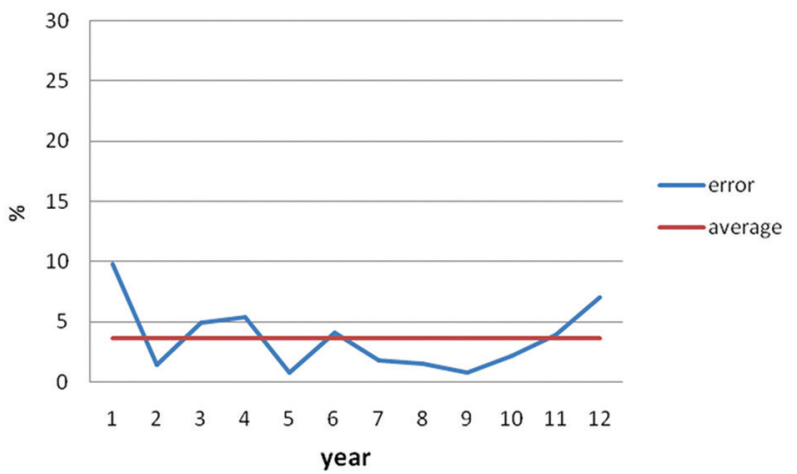

Fig. 11. Model error for the correct amount tiles per months of 2006.

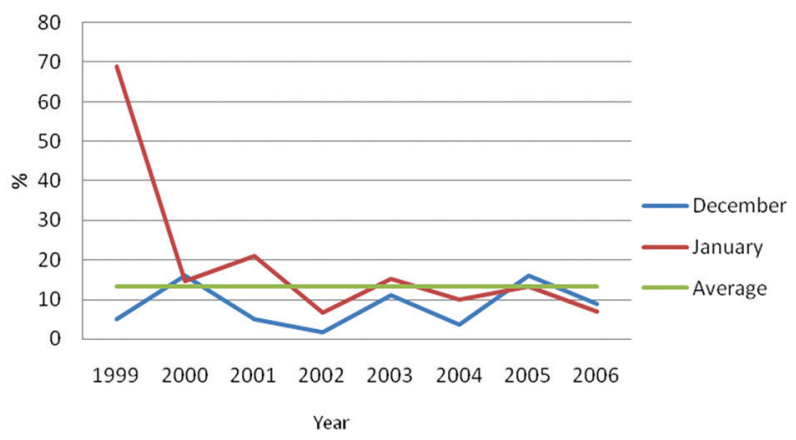

Fig. 12. Model error (\%) of the correct amount of tiles in December and January for several years. 


\subsection{MODEL RESULTS FOR WASTE TILES}

The results obtained by model are compared with the values of the production process for the percentage of waste tiles. The results obtained by a simple model based on neural network with 20 neurons in the hidden layer for 11 input variables and the known output values are calculated for waste tiles in 1999, 2000, $2001,2002,2003,2004,2005$ and 2006. The percentage of waste tiles derived from the neural network and the percentage of waste tiles in real production in the period from 1999-2006 are shown in Fig. 13.

The absolute model error of waste tiles was calculated. The percentage of model results in relation to the percentage of produced waste tiles is obtained as the difference of these values. The average model error for the amount of waste tiles in period 1999-2006 of the simple model based on neural network is shown in Fig. 14.

The model error varies by month. The smallest model error was obtained in 1999 when it was $0.1 \%$ but in 2005 was around to $4.13 \%$.

If the movement of the percentage of waste tiles generated from the process and percentage of waste tiles from the model is observed from 1999 until 2002, the model gives lower values than those from the process. During the period since 2002 to 2006 the model provides a higher percentage of waste tiles than from production. The average absolute model error of waste tiles per year is around $1.7 \%$.

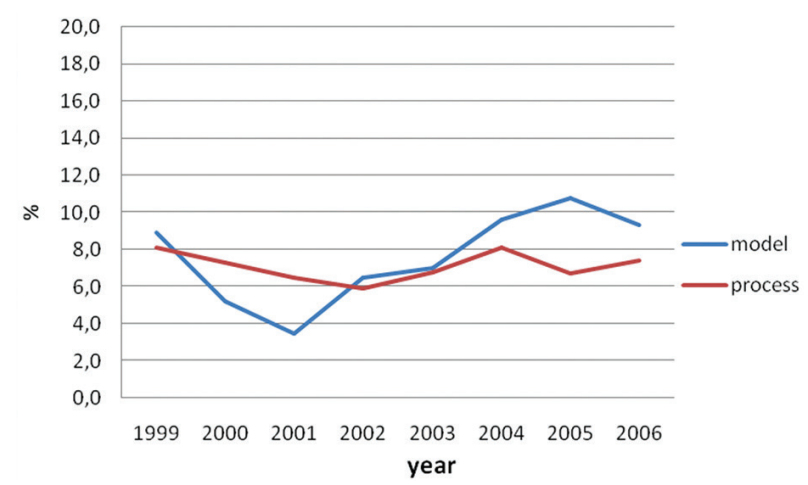

Fig. 13. Percentages of waste tiles obtained by model compared to real values per year.

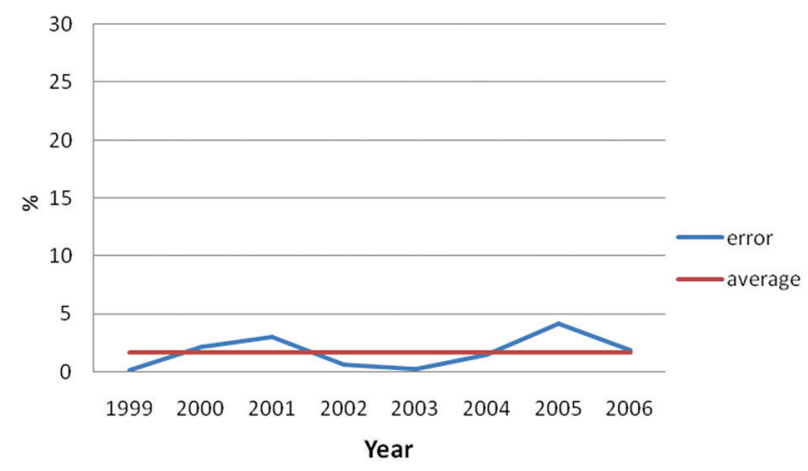

Fig. 14. Model error of waste tiles in period 1999 - 2006.

\section{CONCLUSION}

This paper presents a simple mathematical model of the production process based on static neural networks in ceramic tiles industry. The research of the best neural network structure is done by learning process or trainings with known standardized inputs and outputs by changing the network parameters to get the best results. The best simple model is obtained by ninth learning with 20 neurons in the hidden layer for neural network with 11 inputs and 2 outputs. The model is applied and calculated for the eight years of production. The resulting model error for the correct tiles is in average around $6.4 \%$ and $1.7 \%$ for waste tiles. The monitoring period from 1999 until 2006 is limited and could not be continued to next years as the real data after are not more available because the factory changed the owner and now does not produces.

The simple model can be used to predict the environmental impact of production on the amount and percentage of correct and waste tiles. The application of this new approach can produce better control effect of ceramic industry to the environment.

The simple model using static neural network enables the prediction of environmental impact of the production process of ceramic tiles. The developed simple model could be used in simulation of the influence of input variables: clay, dolomite mud, electrolytes, water, gas used in atomizer, gas for drying tiles, frit, engobe, pigments, gas for firing and other raw materials on two output variables. It is possible to test the influence of reduction in some of the inputs to percentage and the amount of the correct and waste tiles.

The quantity of correct tiles depends on used technology and equipment. The presented model can predict the quantities of produced correct and waste tiles using new equipment or new technologies. The presented model could be used to similar production processes for prediction and improving management.

\section{REFERENCES}

[1] R. Rojas, "Neural Networks: A Systematic Introduction", Springer-Verlang Berlin, 1996.

[2] I. Petrović, M. Baotić, N. Perić, “Regularization and validation of neural network models of nonlinear systems", Elektrotechnik und Informationstechnik, Vol. 117, No. 1, 2000, pp. 24-31.

[3] M. Baotić, I. Petrović, N. Perić, "Convex Optimization in Training of CMAC Neural Networks", Automatika, Vol. 42, No. 3-4, 2001, pp. 151-157.

[4] M. Barić, I. Petrović, N. Perić, "Neural network based sliding mode control of electronic throttle", Proceedings of the IFAC Symposium on Advances 
in Automotive Control, Salerno, Italy, 19-23 April 2004, pp. 176-182.

[5] J. Matuško, I. Petrović, N. Perić, "Neural network based tire/road friction force estimation", Engineering Applications of Artificial Intelligence, Vol. 21, No. 3, 2008, pp. 442-456.

[6] V. Spudić, M. Marić, N. Perić, "Neural networks based prediction of wind gusts", Proceeding of the European Wind Energy Conference EWEC, Marseille, France, 16-19 March 2009, pp. 2-9.

[7] T. Keser, Ž. Hocenski, V. Hocenski, "Intelligent Machine Vision System for Automated Quality Control in Ceramic Tiles Industry", Strojarstvo, Vol. 51, No. 5, 2010, pp. 101-110.

[8] A. Elshafie, O. Karim, M. R. Taha, "Non-Linear Prediction Model for Scour and Air Entrainment Based Static Neural Network Approach", European Journal of Scientific Research, Vol. 27, No. 3, 2009, pp. 400-416.

[9] R. P. Deshmukh, A. A. Ghatot, "Short Term Flood Forecasting Using RBF Static Neural Network Modeling a Comparative Study", International Journal of Computer Science and Information Security, Vol. 8, No. 6, 2010, pp. 93-98.

[10] M. Hadzima-Nyarko, E. K. Nyarko, N. Ademović, I. Miličević, T. Kalman Šipoš, "Modelling the Influence of Waste Rubber on Compressive Strength of Concrete by Artificial Neural Networks", Materials, Vol. 12, No. 4, 2019, pp. 1-18.

[11] M. Nikoo, F. Ramezani, M. Hadzima - Nyarko, E. K. Nyarko, "Flood-routing modeling with neural network optimized by social-based algorithm", Natural hazards, Vol. 82, No.1, 2016, pp. 1-24.
[12] I. Barić, R. Grbić, E. K. Nyarko, "Short-Term Forecasting of Electricity Consumption Using Artificial Neural Networks - an Overview", Proceedings of the 42nd International Convention on Information and Communication Technology, Electronics and Microelectronics, Opatija, Croatia, 20-24 May 2019, pp. 1076-1081.

[13] "HRN EN 14 411: 2004 Keramičke pločiceDefinicije, razradba, značajke i označavanje" (EN 14 411:2006, Second edition, December 2008)

[14] "HRN ISO 9001: Sustavi upravljanja kvalitetomZahtjevi" (ISO 9001: 2008; EN ISO 9001: 2008), Fifth Edition, April 2009.

[15] "HRN EN ISO 14001: Sustavi upravljanja okolišomZahtjevi sa uputama za primjenu" (ISO 14001: 2004, EN ISO 14001:2004), Third Edition, April 2009.

[16] V. Hocenski, "Novi pristup smanjenju utjecaja keramičke industrije na okoliš temeljen na neuronskim mrežama", University of Zagreb, Faculty of chemical engineering and technology, Zagreb, Croatia, PhD Thesis, 2012. (In Croatian)

[17] "Reference Document on Best Available Techniques in the Ceramic manufacturing industry, EU Commission", August 2007, https://eippcb. jrc.ec.europa.eu/sites/default/files/2019-11/cer_ bref_0807.pdf (accesed: 2020)

[18] V. Hocenski, Ž. Hocenski, S. Vasilić, "Application of Results of Ceramic Tiles Life Cycle Assessment due to Energy Savings and Environment Protection", Proceedings of the IEEE International Conference on Industrial Technology, Mumbai, India, 15-17 December 2006, pp. 2972-2977 